Frank Heinemann, Charles N. Noussair

\title{
Macroeconomic experiments
}

Journal article | Accepted manuscript (Postprint)

This version is available at https://doi.org/10.14279/depositonce-9230

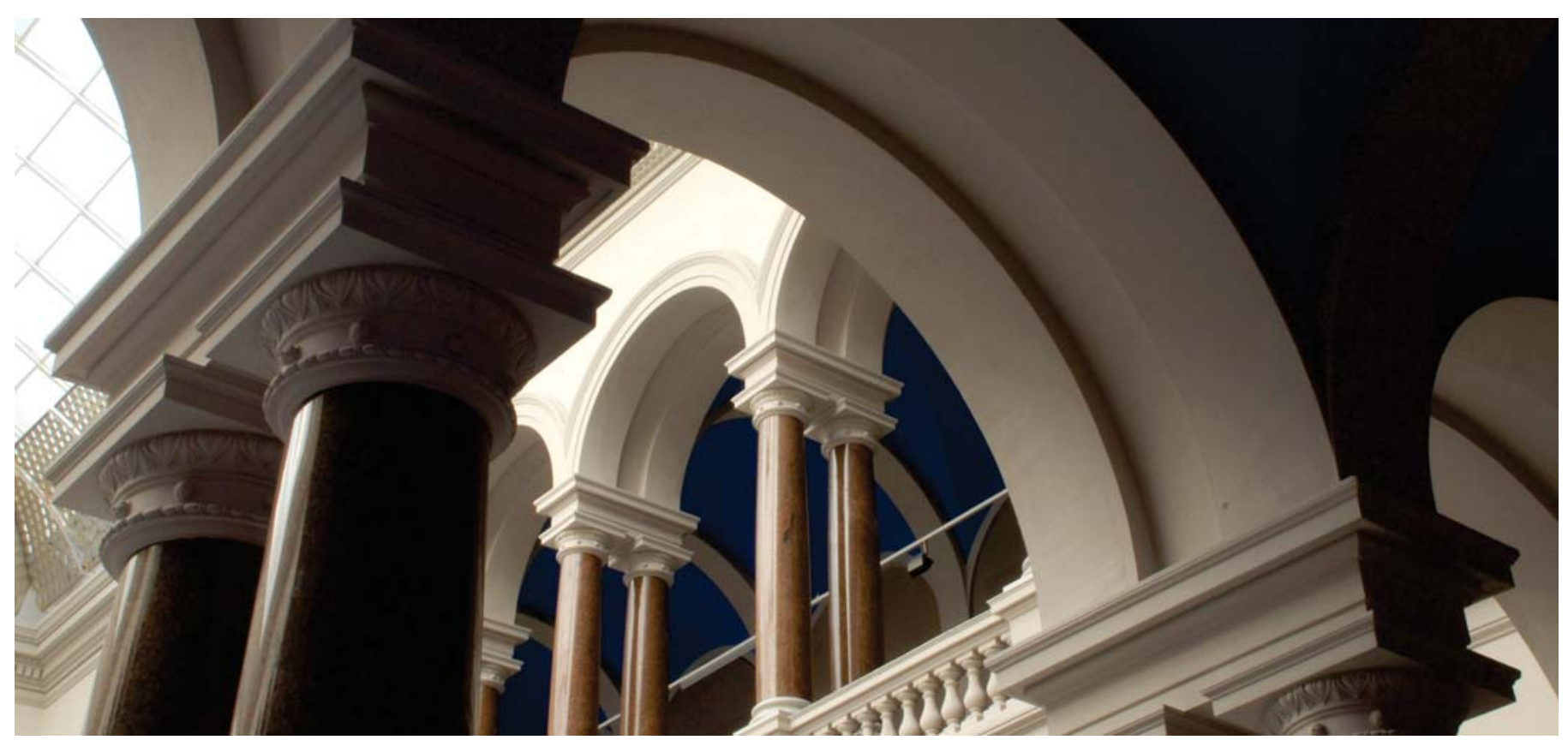

Heinemann, F., \& Noussair, C. (2015). Macroeconomic experiments. Journal of Economic Studies, 42(6), 930-942. https://doi.org/10.1108/jes-09-2015-0171 


\title{
Macroeconomic Experiments
}

\author{
Frank Heinemann ${ }^{1}$ and Charles N. Noussair ${ }^{2}$
}

September 2015

\section{Introduction}

Experimental macroeconomics encompasses several strands of research. Their common feature is that the methodology of experimentation is applied to a topic that is generally considered to be within the domain of macroeconomics. While experimental work has not had the impressive impact on macroeconomics that it has had on decision or game theory, it retains the potential to do so. Here, we argue that experimental economics is a flexible methodology which can be applied in different ways to numerous macroeconomic research questions and because it is useful for improving theory and designing macroeconomic policy. Indeed, experimental methods have already been used to study several classes of macroeconomic models. This introduction discusses the rationale for conducting macroeconomic experiments, some considerations of experimental design, and the possibilities of what can be learned from the method. It introduces the four contributions that comprise the remainder of this symposium. These contributions are examples that illustrate the breadth of the areas with macroeconomics on which experimental methods can be brought to bear.

To specify the set of research that falls under the rubric of experimental macroeconomics, one must delineate the boundaries of both macroeconomics and experimental economics. Macroeconomics is traditionally defined as the study of the economy at the aggregate level. This is typically taken to encompass microeconomic phenomena that have relevance to the macroeconomy, because the movement toward microfounded macro models has blurred the distinction between

\footnotetext{
${ }^{1}$ Department of Economics, Technische Universität Berlin, 10623 Berlin, Germany, E-mail: frank.heinemann@tu-berlin.de.

${ }^{2}$ Department of Economics, Tilburg University, P. O. Box 90153, 5000 LE Tilburg, The Netherlands. E-mail: C.N.Noussair@uvt.nl.
} 
micro and macro. Part of the domain of macroeconomics concerns aggregates such as inflation, national output, and interest rates, but it also includes studying the determinants of these aggregates. As in other fields of economics, any definition of macroeconomics is to some extent a result of selfidentification and self-classification on the part of researchers.

Experimental economics can be defined as the creation and study of synthetic economic situations, in which human participants make decisions, for the purpose of answering one or more specific research questions. The fact that human participants are present is crucial and serves as the primary feature distinguishing experimental methods from calibration exercises, agent-based modeling, or models based purely on rationality postulates. In this article, we restrict the discussion to conventional laboratory experiments (Harrison and List, 2004). These are studies that adhere to the methodology that is described in section two.

Duffy $(2014$, p.3) defines "a macroeconomic experiment as one that tests the predictions of a macroeconomic model or its assumptions, or is framed in the language of macroeconomics, involving for example, intertemporal consumption and savings decisions, inflation and unemployment, economic growth, bank runs, monetary exchange, monetary or fiscal policy and any other macroeconomic phenomena". The main substantive contributions of experimental macroeconomics to date are ably surveyed by Ochs (1995), Ricciuti (2008), and Duffy (2014). Cornand and Heinemann (2014) survey experiments related to monetary policy.

\section{Economic experiments: what are they?}

Experimental economies are created for research purposes and are characterized by human agents making some or all of the decisions that affect outcomes in the economy. In a conventional laboratory experiment, student subjects are the participants, and assume the role of an actor in the economic model under investigation. Such roles may be those of producer, consumer, worker, social planner, central banker, etc... The subjects receive a monetary payment for their participation. The 
payment is monotonic in the respective agent's objective function that is taken from the theoretical model being studied. In this way, the researchers can induce desired incentives on the part of the agent. However, there remain two important differences between theory and experiment. Theory assumes that the agent maximizes an objective function (or in a behavioral model, applies a specific decision rule). The experimental subject has an incentive to act in accordance with maximizing the objective function, but she is free to choose otherwise. Second, macroeconomic theories need to specify an equilibrium concept for closing the model. Such equilibria can be phrased as assumptions about agents' beliefs about other agents' behavior. In an experimental economy, subjects' beliefs are real, priors may differ between subjects, and belief updating on information deviates from rationality in patterns that may be stable over a large set of situations. In a repeated game, subject's actions usually do not constitute an equilibrium from the outset and it can be investigated whether they converge to any equilibrium, and if so, which equilibrium concept is appropriate.

The physical setting of an experimental session usually finds subjects at computer terminals, isolated in a manner such that their decisions cannot be seen by other participants, and generally located in a room that is a dedicated facility for economic experiments. This facility is physically organized in such a way as to allow the researcher to control the available sets and timing of information and activity. This control facilitates the creation of an environment that reproduces aspects of a theoretical model, and identifies causal links between events. Standard software platforms for conducting economic experiments (e.g. Z-Tree, developed by Fischbacher, 2007) ease the design of experiments and their implementation in laboratories, and allow comparable modes of investigation across different groups of researchers.

In a typical experimental setting, subjects are recruited in advance to participate for a predetermined period of time without knowing the purpose of the experiment. At the outset of the session, training in the appropriate software application is given if necessary, and then the instructions for the experiment itself are distributed. They are often read aloud to increase comprehension and to 
make it common knowledge that all subjects are playing by the same rules. The data gathering phase then begins. This usually involves subjects making decisions over a series of discrete periods. These sometimes follow one or more periods of practice that do not count toward subject earnings. Subjects are paid at the conclusion of the session in cash or by bank transfer. A typical session lasts between 30 minutes and 4.5 hours. Longer sessions are usually conducted over multiple days.

An experiment is usually designed in a manner to make it comparable either to prior experiments, to a theoretical model, or to a field setting ${ }^{3}$. The use of university students as participants is an accepted, and indeed arguably a desirable, practice in experimental economics. It facilitates replication by competing research groups because students comprise a large subject pool that is accessible to most researchers. The widespread use of participants that are similar in profile makes it easier to compare different studies to each other since it eliminates one source of confounding effects.

Whether there is a difference between the behavior of student subjects and the non-student agents who make decisions in the field, is an important question. Undoubtedly, there exist some settings and some field populations where such differences appear. The relevant question is whether or not such a difference is widespread or systematic. Frechette (2008) surveys thirteen studies, in which students and professionals participate in the same task, and finds that there are some instances in which they differ, but the differences do not follow a consistent pattern. For example, professionals do not systematically make better decisions than students in terms of the money they are able to earn, nor do they tend to generate outcomes that conform more to particular economic theories. In other words, provided that the two populations are playing the same game, students and professionals do not behave very differently.

Cornand and Heinemann (2015a) list four justifications for studying student subjects' behavior in experimental economies resembling field economies with professional decision makers: (1) some

\footnotetext{
${ }^{3}$ The field refers to the world outside the laboratory. Many economists casually refer to a distinction between the laboratory and the real world. Experimental economists, who think of laboratory economies as just as real, albeit synthetic, as their naturally occurring counterparts, often prefer the term field.
} 
biases, heuristics, and fallacies are common amongst all humans. How they affect the outcome in an interactive environment does therefore not depend on the subject pool. (2) The qualitative results from comparing different treatments may be the same for different types of subjects, even if these types affect the levels in all treatments. (3) "[T]he relation between expert knowledge (...) and the complexity of real economies may be comparable to the relation between the comprehension of models by students and the complexity of these model economies [in the laboratory]." (Cornand and Heinemann, 2015a, p. 182). (4) The lab is a perfect environment for testing incentive effects. To the extent that professionals are thought of responding to incentives, the laboratory is an ideal environment for testing how different incentive schemes affect behavior.

The key comparison for model evaluation is between the decisions of subjects and the agents described in the theoretical model corresponding to the experiment. Here the observed level of conformity depends on the theoretical model that one considers. There are three principal sources of differences. First, in many applications, decisions may differ because of limited computational capabilities or behavioral biases on the part of the human agents. These can cause the predictions of models that assume a high level of rationality not to hold. Probability weighting, loss aversion, hyperbolic discounting and other phenomena that are not incorporated into classical models, but are accounted for in some behavioral models, are frequently observed. Second, the assumption of selfinterested agents is often belied by the presence of social preferences, the tendency to take into account the earnings of other agents in the economy. There are well-documented effects of altruism, envy, social welfare preferences, and positive and negative reciprocity. The third force causing deviations from theoretical models is strategic uncertainty. Even if an agent is rational herself, she may doubt that others are also rational. This strategic uncertainty affects the decisions of all parties and causes decisions to differ from those that would be taken if the rationality of agents were common knowledge. The field of behavioral economics is in part inspired by the observation of the three above types of effects in numerous experimental studies. 
The degree of influence these effects exert on experimental outcomes varies from negligible to overwhelming depending on the model and the way it is implemented. If these forces fail to assert themselves in an experimental test, it is interpreted as support for a model that assumes them not to exist. If the effects appear in an experiment and influence outcomes significantly, it is supportive of a model that takes the same behavioral forces into account.

\section{The benefits of an experimental approach}

In general, any empirical methodology that can be meaningfully brought to bear on an economic research question, such as econometrics, experimental economics, agent-based modeling, or model calibration, may be beneficial. Experiments are typically complementary to one or more of these approaches for most research questions. Whether they have an advantage over other empirical methodologies, and where such an advantage may lie, depends on the specific research question being asked. Ricciuti (2008) emphasizes the value of conducting experiments in tandem with economic theory, to shed light on issues on which a theoretical model is silent. These include the dynamic patterns whereby an economy approaches an equilibrium, the process whereby expectations are formed and updated, the manner in which coordination is achieved, and how the complexity of an economy affects the accuracy of a model's predictions.

Every empirical methodology, and experimental economics is no exception, is infeasible for considering some issues. The main limitation of experimental research is that it is restricted by technological and budget constraints to the settings that are feasible to implement in the laboratory. This prevents the study of some questions of interest. For example, it is not possible with current experimental methods to simulate field macroeconomies, such as producing a reproduction of the economy of the United States or of the European Union. An experiment cannot tell you whether world GDP will increase or decrease next year. Assessing the extent to which experimental results are relevant to field economies requires the researcher to understand why particular outcomes are observed in the laboratory. If one can characterize the behavioral principles that are generating the 
laboratory data, then one can consider whether these principles are likely to be robust to the differences between experimental and field economies, such as of scale, complexity, context, incentives, and the characteristics of agents in the economy. If so, macroeconomic models can be improved by accounting for behavioral patters.

Experimental data offer many of the same advantages compared to field data that calibration exercises or agent-based models do. Agent-based models rely on well-defined types of agents that differ in their responses to information. They can be directly tested in the lab and experimental results can be used to estimate distributions of types and parameters of dynamic adjustments.

(1) The first advantage is that the experimental researcher observes some variables that are unobservable to econometricians working with field data. Some underlying structural parameters of an economy, such as demand, production, and cost functions, and therefore equilibrium prices and quantities, can be directly observed, rather than estimated. One advantage of this observability is that point predictions of theoretical solutions can often be computed. For example, competitive equilibrium prices and quantities can be calculated and compared to the prices and quantities generated in the experimental economy.

(2) In addition to these underlying structural parameters, some behavioral parameters can also be measured directly in an incentivized manner that would otherwise not be possible. For example, in field research expectations and risk attitudes can be measured with survey questions or inferred from consumption, investment, or other economic decisions. Experimental protocols have been developed to directly elicit beliefs about underlying values or future expectations of economic variables. These procedures have the feature that participants have monetary incentives to report truthfully. As a consequence, the study of how individuals form expectations in various macroeconomic environments has been a focus of experimental research. Similarly, risk attitudes can be elicited and measured. Both 
beliefs and risk aversion measures can then be linked to behavior within an experimental macroeconomic environment at the individual level. ${ }^{4}$

(3) In addition to observing the underlying structure of the economy, the researcher can specify and control it. This has a number of desirable consequences. One is that the underlying structure of an economic model can often be reproduced. For example, a two-country world, in which there are exactly two sectors in each country, can be constructed. This facilitates the application of two-country theoretical models of international trade. Cobb-Douglas and Constant Elasticity of Substitution production or demand functions can be imposed on the economy, symmetric firms can be created, etc... This sometimes allows theoretical predictions to be computed more easily.

(4) The control experimental methods allows the researcher to evaluate a change in one parameter while keeping all else constant. For example, consider studying the effect of a shock to labor productivity or to demand for a good. In empirical data sets, such changes often occur concurrently with changes in other variables. In an experiment, however, the researcher can change one parameter of interest, allowing such confounds to be avoided. Thereby, impulse response functions can be tested directly.

(5) The ability to vary one parameter exogenously allows the direction of causality to be established in the relationship between two variables. For example, it is difficult to know whether a correlation between increased international trade and higher productivity is caused by the first or the second variable, or whether both variables are being influenced by a third variable. In an experiment, one

\footnotetext{
${ }^{4}$ Experimental methods have been widely used to elicit independent estimates of risk aversion coefficients and discount rate parameters (Binswanger, 1980; Kachelmeier and Shehata, 1982; Holt and Laury, 2002; Andersen et al., 2007). These experiments are not themselves designed to be linked to specific macroeconomic models. However, such experimentally-measured estimates are potentially useful for use as inputs in calibration exercises and in agent-based models, where the estimates typically used come from empirical studies using field data.
} 
variable can be changed by the experimenter, and the effect of this change on other variables can be readily identified.

(6) The control methods are also used to test comparative statics predictions. Comparing two treatments that differ only in one institutional setting or in the size of one exogenous parameter establishes a clear causal relationship and provides an opportunity for bench-testing institutional changes in the laboratory.

(7) The quality of data available from an experiment can often exceed that which could otherwise be obtained. In an experiment, macroeconomic data, such as GDP and price indices, can be measured without error.

(8) An experiment can be replicated with multiple samples of participants drawn from the same or similar subject pools. Many independent sessions can be conducted under identical conditions, except for the random effect of drawing different samples from the subject pool. Thus, many copies of identical economies can be created and studied, yielding as many independent observations as desired. This allows the researcher to study the variability of outcomes, because it yields estimates of variance, and of the probability of different outcomes. It also allows the rejection of incorrect null hypotheses at an arbitrary level of significance. A second type of replication that is enabled is the ability for other researchers to run the same experiment themselves and reproduce data under the same conditions in their own laboratories. This serves as a check on the data gathering procedures and analysis and allows some mistakes to be found and corrected.

(9) Cornand and Heinemann (2015a) have argued that experiments can be used for bench-testing monetary policy. Although external validity is obviously limited, experiments are a quick and cheap way for testing whether policy changes have the desired effects at least in a simplified laboratory economy. If not, the question arises, why they should work in a more complex economy outside the lab - and particular attempts to answer this question can also be taken to the laboratory by a revised experimental setting. These arguments can eventually also be applied to fiscal policy measures aiming 
at economic stability, current account balances or growth. "In the ideal case, an economic policy reform is evaluated with all possible scientific methods before a political decision is made. That is, theoretically, experimentally in the lab-and the field, and with traditional applied econometrics." (Riedl, 2010, p. 88).

(10) Experiments often reveal heterogeneity in subjects' preferences, biases from rationality, or heuristics for solving complex decision problems. Recent developments in macroeconomic theory aim to account for heterogeneity. Here, the experimental evidence may guide theory and help calibrating macro models with respect to the distribution of agents' relevant characteristics.

\section{The relation between theory and experiment}

The successful lines of research in experimental macroeconomics have tended to be closely linked to theoretical models. This brings up the issue of whether it is problematic that the macroeconomies that we are ultimately interested in understanding are much larger in scale and more complex than experimental economies. Of course, the same issue also arises in the interpretation of theoretical models, which are also typically highly stylized. Indeed, it can be argued that theoretical models deviate even more from field settings than do experiments, since these not only simplify the structure of the economy relative to naturally occurring ones, but also impose more assumptions on the objectives and behavior of agents. However, for both theoretical modeling and experimental research, one of the strengths of the method is that the economy is simplified sufficiently so that its workings can be analyzed and understood. Neither method presumes to capture all of the complexity that characterizes field economies and attempts to simulate them.

One view of the connection between theoretical modeling, laboratory experiments, and field economies is articulated by Noussair et al. (1995). They write "Laboratory research deals with the general theories and the general principles that are supposed to apply to all economies, the economies found in the field as well as those created in a laboratory. The laboratory economies are very simple and are special cases of the broad class of (often complex) economies to which the general theories are 
supposed to be of relevance. If a general theory does not work successfully to explain behavior in the simple and special cases of the laboratory, then it is not general. When a model is found not working, opportunity exists to modify the theory to account for the data or to reject the theory. Thus, the laboratory provides an arena in which competing notions and theories about the nature of human (and market) capacities can be joined with data. ${ }^{\text {"5 }}$

This view describes an iterative interaction between the development of new theory, its evaluation through experimental studies, and its modification to account for data when the evidence against the theory becomes sufficiently convincing. Indeed, while economic experiments can be conducted for several different scientific and policy purposes (see Smith, 1994, for a list and discussion of the reasons for conducting experiments), experiments that consider themselves macroeconomic have predominantly involved creating experimental environments close to a theoretical model. Solutions to the theoretical model, typically optima or equilibria, are taken as null hypotheses and tested with the experimental data.

A schematic of one way to view the relationship between an experiment and its parallel theoretical model is illustrated in Figure 1. An economic model can be thought of as postulating a relationship between an underlying economic structure (Row 1), interacting with assumptions on agents' objectives and beliefs (Row 2), to determine economic outcomes (Row 3). In other words, an economic model makes a statement that "If the structure of the economy is $X$, and agents behave according to the principles of $\mathrm{Y}$, the outcomes in the economy are $\mathrm{Z}(\mathrm{X}, \mathrm{Y})$." As illustrated in Column 2 , a theoretical model specifies the structure and the behavioral assumptions, and uses logical reasoning to derive properties of the resulting outcome.

\footnotetext{
${ }^{5}$ This quote applies to the important questions raised by having a small number of agents participating in an experimental economy. One possible view of the domain of macroeconomics is that it applies only to economies populated by a large number of agents. Indeed, macroeconomic models are generally inspired by the desire to explain aggregate phenomena. However, these models often do not specify the number of agents required for their model to apply, and thus, literally interpreted, are equally relevant for 5 or 50000000 agents. Indeed, assuming that the economy behaves like a social planner, and thus like one unitary agent, is common in classical models.
} 
The structure of the economy, represented in the first row of the figure, consists of all elements of the model other than the assumptions on behavior. This includes the incentives, technological constraints, and rules of interaction in the economy. ${ }^{6}$ In a theoretical model, these are often completely specified. The incentives consist of the objective functions of various agents. For a consumer, this includes the utility of consumption and in a dynamic model, assumptions on how she values future payoffs. A firm is typically assumed to maximize profit over some time horizon. Constraints are imposed in the form of production functions and budget limitations on consumers, which can include the existence of borrowing constraints. The structure of the economy also includes any description about the timing of decisions and information availability. In an individual choice problem, the structure of the economy reduces to the decision problem that the unitary agent faces. In a multiple-player interaction, the structure can be thought of as the normal or extensive form, the rules of the game whereby players interact.

The second piece of an economic model is the set of assumptions on behavior and beliefs of agents. This is illustrated in the second row of Figure 1. Under a traditional approach in macroeconomics, agents are assumed to maximize their own payoffs without regard to the consequences to other individuals. The standard assumption on expectations is that they are rational, but alternative expectational assumptions have been proposed and studied (see for example Evans and Honkapohja, 2001). The last piece of the model is the outcome, shown in the last row. This outcome depends on the solution concept of the model and may consist of one or more equilibria,

\footnotetext{
${ }^{6}$ Smith (1982) proposes a framework to describe and interpret microeconomic experimentation. His framework has become widely accepted in the research community. In his construction, the behavior of an economy is a function of its environment and its institutions. The environment corresponds to the incentives and constraints in the economy, and the institution refers to the rules of interaction. In the schematic shown in figure 1, the structure of the economy encompasses both the environment and the institutions. In some macroeconomic models the institutions are precisely described, with the timing of activity and information available by each agent specified. In other types of macroeconomic models, such as classical growth or some DSGE models, some details, such as the market clearing mechanism, are left unspecified. In such situations, there is relative freedom for the experimentalist to choose institutions while remaining consistent with the model.
} 
optimal solutions, or the outcome of a simulation. These outcomes can serve as hypotheses to be tested against the data generated in an experiment constructed to conform to the model.

In theoretical modeling, shown in the second column of the figure, the economist specifies the structure and manner in which economic actors make their decisions, and derives the resulting outcome (agent-based modeling is similar, but usually with a more complex structure and different assumptions on behavior). In an experiment, shown in the last column of the figure, the researcher also specifies the environment, but does not impose any behavioral assumptions. Maximization of an objective function is not typically imposed in an experiment, as it is in a theoretical model. Rather, what is done is to give individuals a monetary incentive to attain greater values of an objective function. The greater the realized value of the objective function, the greater the monetary payment to the subject. The second row on the table corresponds to whatever subjects do in the experiment. The output is measured and can be compared against theoretical benchmarks.

The structure of the experimental economy varies, depending on the particular experiment, in the degree of conformity to the theoretical model under consideration. That is, the differences between Columns 2 and 3 in Row 1 may be minimal or substantial. The experiment allows some or full freedom for agent behavior. The relaxation of the constraints on behavior imposed in a theoretical model captures the essence of what can be learned about a theoretical model from experimental investigation. Suppose that the behavioral assumptions of a theoretical model are replaced with the behavior that actual individuals generate. In other words, suppose that for Row 2, Column 2 is replaced by Column 3. To what extent do the outcomes of the theoretical model in Row 3 Column 2, interpreted as predictions of the model, describe the outcomes of the experimental economy in Row 3 of Column 3 ?

A fundamental issue in the design of a macroeconomic experiment is how closely to require the structural assumptions to adhere to those in a theoretical model. How faithfully should Row 1, Column 3, of Figure 1 conform to the second column of the first row? Exact replication of the structure 
of a model within a functioning laboratory economy may not be feasible in many cases. For example, consider a general equilibrium model, in which markets for output and factors of production are assumed to clear simultaneously. In an economy populated with live producers and consumers, this is not possible. ${ }^{7}$ Producers must purchase the factors, subsequently engage in a production process, and then sell the output on another market. ${ }^{8}$ Alternatively, they might contract to sell output at a negotiated price before making purchases in the input market. In a functioning experimental economy, it may be necessary to allow asynchronous events when timing is not fully specified in the theoretical model.

If the structure of the experimental economy is sufficiently close to the theoretical model, one could plausibly argue that the experiment is, in an important sense, testing behavioral assumptions of the model. This is an important advantage over testing models with field data, where rejecting a model does not tell us which part of the model is responsible for the rejection. In other cases, the experimental economy may only loosely resemble the model, but the model can still serve a source of hypotheses, and it is these hypotheses, rather than the model itself, that can be said to be tested in the experiment.

The latter research strategy, using a model to generate hypotheses for testing, rather than testing the model's point predictions, is common in non-laboratory economic research. Applied economic models are intended to generate hypothesis about some class of related economies. The class of economies might be quite expansive. Empirical research with field data is conducted in this vein. Data are acquired from the field, and predictions from a model are tested. There is no claim that

\footnotetext{
${ }^{7}$ Cash in advance models (see for example Lucas, 1982) were an attempt to deal with similar explicit issues of timing.

${ }^{8} \mathrm{~A}$ requirement that inputs trade before the outputs they produce has an effect on prices, in that it makes input prices lower than marginal revenue products (Noussair et al., 1995, 2007; Riedl and van Winden, 2001, 2007). This appears to be because of the risk that producers take on in purchasing inputs for use in producing outputs which trade later on at a price that is unknown at the time of the input market transaction. To compensate producers for this risk, they are able to earn a premium resulting from relatively low input prices in conjunction with relatively high output prices. This premium decreases over time within an experimental session, as prices stabilize, reducing the risk to producers.
} 
the field data satisfy the assumptions of the model, but if the hypotheses are not rejected in the data, it can be argued that the model may be relevant in describing the field setting. As an example, consider an optimal growth model, such as that formulated by Ramsey (1928). While it is implausible to argue that any of the world's economies have the structure of the model, it makes specific predictions that can be tested. The model predicts, for example, that poor countries have a rate of growth that is faster than rich ones. This implication of the model can be evaluated with field data. If the prediction is supported, it can be argued that the model is of relevance. A similar approach can be taken in experimental macroeconomics. A model is used to generate hypotheses about what would happen in an experimental economy, and these hypotheses are evaluated against the data. ${ }^{9}$

In many theoretical models, some institutional details are excluded from the description of the economic structure in order to achieve tractability and to allow the model to focus on the effect of a smaller number of variables. In such cases, there is greater scope for creating an economy consistent with the model. One important way for an experiment to supplement the content of a model is to add a rich market context to the setting. Rather than assuming market clearing, participants are required to actively buy and sell goods on terms agreed upon with other participants. They are thus free to make mistakes, marginalize, collude, or behave as price-takers. This allows the researcher to establish how robust a model is to the inclusion of the rich market context, an important feature of all functioning economies outside of the laboratory.

\footnotetext{
${ }^{9}$ Although the primary sources of hypotheses are theoretical models, hypotheses may also come from prior experimental results, or from stylized empirical facts from the field. It is also possible to test a macroeconomic hypothesis that is independent of an underlying model. Consider the assertion that "inflation and unemployment are negatively correlated", and its use as a hypothesis about behavior in an experimental economy. This relationship can be generated within a rigorous New Keynesian model, but can be asserted for any economy in which inflation and unemployment can be measured. If the relationship is observed in many different experimental designs, one can claim that the hypothesis is supported in a broad class of economies.
} 
Figure 1: Economic Models; Structure, Agent Behavior, and Outcome, Theoretical and Experimental
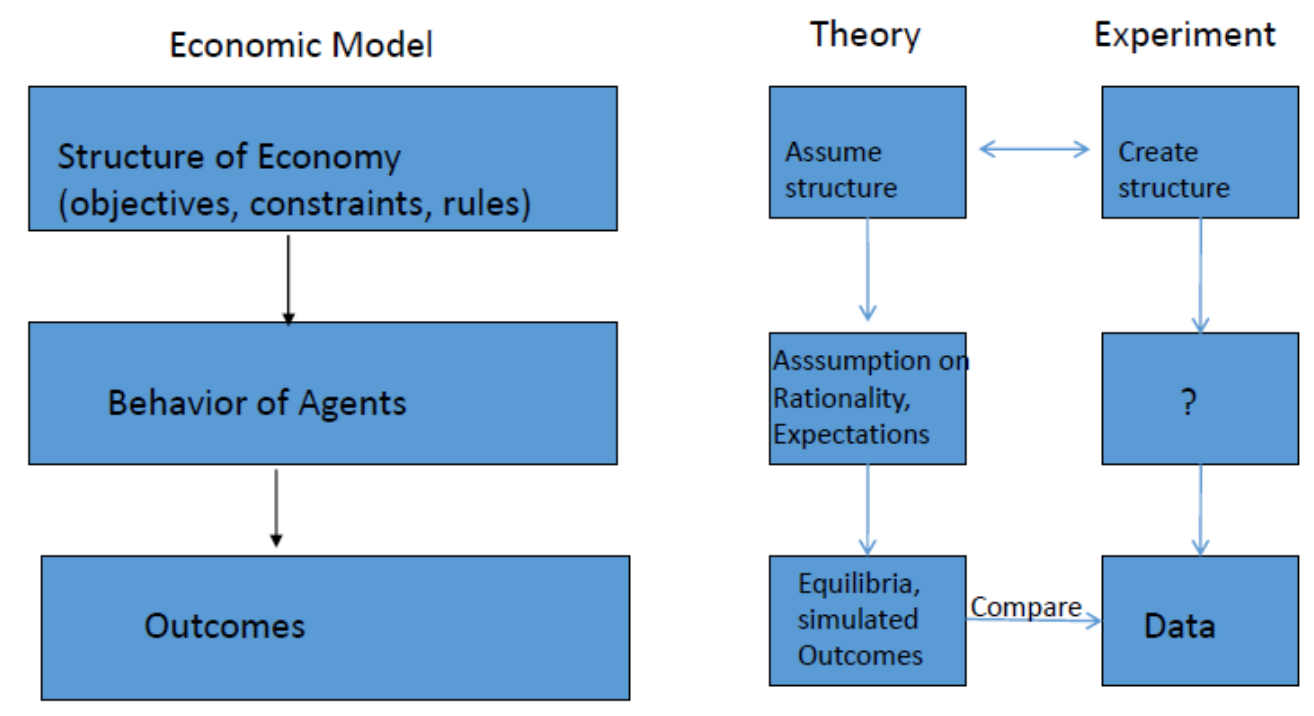

\section{This symposium}

The first paper in this symposium, "Banking on Experiments", by Martin Dufwenberg (2015) provides a discussion of what can be learned from experimental work to help researchers understand banking crises. Dufwenberg argues that experiments can be used to make causal inferences about the relationship between economic variables, and can be a useful means to communicate with theorists and policymakers. He surveys two lines of experimental research on banking that have been very active and productive. The first is a literature, beginning with the seminal work of Smith et al. (1988), on the determinants of mispricing in experimental asset markets. This literature seeks to understand a pervasive bubble and crash pattern that appears in experimental markets for long-lived assets. The second is a literature trying to understand how bank runs come about. Most of this literature is inspired by the seminal model of Diamond and Dybvig (1983), and the experimental literature that it has spawned. The paper then moves on to a discussion of banking solvency and concludes with some policy recommendations and potential uses for experiment to study banking crises. 
The paper by Petersen (2015), entitled "Do Expectations and Decisions Respond to Monetary Policy" reports data from experimental general equilibrium production economies. These are economies containing input as well as output markets. Petersen studies factors that make monetary policy more or less effective. The focus is on how agents' beliefs and decisions, and in turn macroeconomic outcomes, respond to nominal interest rate shocks. In one treatment, human participants are in the role of firms and consumers are automated, programmed to play rationally. In a second treatment participants are consumers interacting with automated firms. In the third treatment, human subjects are in both roles. In addition to consuming and producing, subjects also submit expectations, elicited in an incentive compatible manner, about subsequent interest rates. The paper reports that monetary policy has real effects in all conditions. Human households deviate substantially from theoretical predictions, and as a consequence the size and direction of the economy's response to interest rate changes becomes more unpredictable. Subjects tend to form adaptive expectations.

The third paper, by Cornand and Heinemann (2015b) analyzes the implications of experimental results for the welfare effects of transparency. Many macroeconomic environments are characterized by strategic complementarities. In such environments, private agents have incentives to coordinate their activities and public signals may become focal points and exert an influence that is stronger than justified by the informational value of these signals in a Bayesian updating process. In equilibrium the presence of public signals may reduce expected welfare. In an experiment, Cornand and Heinemann (2014) have shown that behavior can be better described by a cognitive hierarchy model than by Nash equilibrium. Subjects seem to realize the focal character of public signals and, hence, put a larger weight on them than on equally informative private signals. However, subjects do not account for the fact that other subjects also put a higher weight on public signals. Cornand and Heinemann (2015b) takes this result back into theory, modify the model accordingly and show that it implies that public signals cannot reduce expected welfare. 
The fourth paper, by Noussair and Xu (2015) concerns the topic of contagion in the pricing of assets. In the experiment they study, there are two assets, whose fundamental values may be positively or negatively correlated, as well as uncorrelated. The correlation information is not publicly known, but in some trials, there are insiders who have private information that allows them to make inferences about the direction of the correlation. The experiment measures the extent to which private information about the correlation is revealed in market prices, and well as the pervasiveness of information mirages. These are market patterns consistent with the revelation of private information, in this case about correlations, when no actual private information exists. The results show that private information tends to be revealed in observed market price correlations, but mirages are also fairly common. These mirages constitute an example of irrational asset price contagion.

\section{References}

Andersen, Steffen, Glenn Harrison, Morten Lau, and Elisabeth Rutström (2008), “Eliciting Risk and Time Preferences," Econometrica 76, 583-618.

Binswanger Hans (1980), "Attitudes Toward Risk, Experimental Measurement in Rural India." American Journal of Agricultural Economics 62, 395-407.

Cornand Camille, and Frank Heinemann (2014), "Measuring Agents' Reaction to Private and Public Information in Games with Strategic Complementarities", Experimental Economics, 17(1), 61-77.

Cornand Camille, and Frank Heinemann (2015a), "Experiments on Monetary Policy and Central Banking," in J. Duffy (ed.), "Experiments in Macroeconomics", Research in Experimental Economics, 17, Emerald Group Publishing, 167-227.

Cornand Camille, and Frank Heinemann (2015b), “Limited Higher Order Beliefs and the Welfare Effects of Public Information", Journal of Economic Studies, forthcoming. 
Diamond, Douglas W., and PhiliOp H. Dybvig (1983), "Bank Runs, Deposit Insurance and Liquidity." Journal of Political Economy, 91(3), 401-419.

Duffy, John (2014), "Macroeconomics: A Survey of Laboratory Research", in $\underline{\text { Handbook of Experimental }}$ Economics Vol. 2, J. Kagel and A.E. Roth, Eds, forthcoming, http://www.upf.edu/leex/ pdf/events/macro survey duffy.pdf [Sep. 10, 2015].

Dufwenberg, Martin (2015), "Banking on Experiments?" Journal of Economic Studies, forthcoming.

Engle-Warnick, James and Nurlan Turdaliev (2010), “An Experimental test of Taylor-Type Rules with Inexperienced Central Bankers", Experimental Economics 13(2), 146-166.

Evans, George, and Seppo Honkapohja (2001), Learning and Expectations in Macroeconomics, Princeton University Press, Princeton, NJ, USA.

Fischbacher, Urs (2007). "z-Tree: Zurich toolbox for ready-made economic experiments," Experimental Economics, 10(2), 171-178.

Fréchette, Guillaume (2008), "Laboratory Experiments: Professionals vs. Students, working paper, New York, New York University.

Harrison Glenn and John List (2004), “Field Experiments”, Journal of Economic Literature 42, 1009-1055. Holt, Charles A., and Susan K. Laury (2002), "Risk Aversion and Incentive Effects," American Economic Review 92, 1644-1655.

Kachelmeier, Steven and Mohamed Shehata (1992), “Examining Risk Preferences Under High Monetary Incentives: Evidence from the People's Republic of China", American Economic Review 82, $1120-1141$.

Lucas, Robert (1982), "Interest Rates and Currency Prices in a Two-Country World", Journal of Monetary Economics 10, $335-359$. 
Noussair, Charles, Charles Plott, and Raymond Riezman (1995), “An Experimental Investigation of the Patterns of International Trade", American Economic Review 85, 462-491.

Noussair, Charles, Charles Plott, and Raymond Riezman (2007), "Production, Trade and Exchange Rates in Large Experimental Economies", European Economic Review, January 2007, 51, 49-76.

Noussair Charles and Yi Long Xu (2015), "Information Mirages and Financial Contagion in an Asset Market Experiment", Journal of Economic Studies, forthcoming.

Ochs, Jack (1995), "Coordination Problems", in The Handbook of Experimental Economics, John Kagel and Alvin Roth eds, Princeton University Press, Princeton, NJ, USA.

Petersen, Luba (2015), "Do Expectations and Decisions Respond to Monetary Policy?" Journal of Economic Studies, forthcoming.

Ramsey, Frank (1928), "A Mathematical Theory of Saving", Economic Journal 38, 543-559.

Ricciuti, Roberto (2008), "Bringing Macroeconomics into the Lab", Journal of Macroeconomics 30(1), 216-237.

Riedl Arno. (2010), "Behavioral and Experimental Economics Do Inform Public Policy," Finanzarchiv 66(1), 65-95.

Riedl, Arno and Frans van Winden (2001), "Does the Wage Tax System Cause Budget Deficits? A Macroeconomic Experiment", Public Choice 109, 371-394.

Riedl, Arno and Frans van Winden (2007), "An Experimental Investigation of Wage Taxation and Unemployment in Closed and Open Economies", European Economic Review 51, 871-900.

Smith, Vernon (1982), "Microeconomic Systems as an Experimental Science", American Economic Review 72, $923-955$.

Smith, Vernon L. (1994), "Economics in the Laboratory", Journal of Economic Perspectives 8, 113-131. 
Smith, Vernon L., Gerry L. Suchanek, and Arlington W. Williams (1988): "Bubbles, Crashes, and Endogenous Expectations in Experimental Spot Asset Markets," Econometrica, 56(5), 1119-1151. 